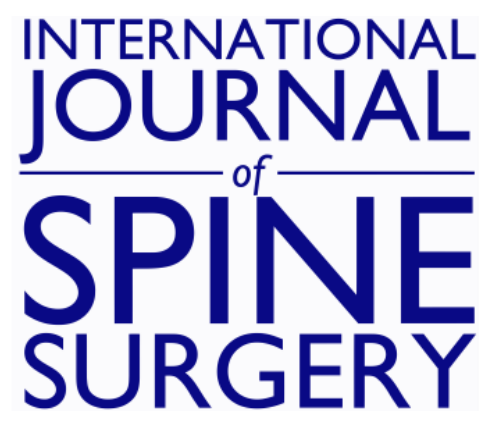

\title{
Editor's Introduction: Update on Current Sacroiliac Joint Fusion Procedures: Implications for Appropriate Current Procedural Terminology Medical Coding
}

MORGAN P. LORIO

Int J Spine Surg 2020, 14 (6) 853-859

doi: https://doi.org/10.14444/7136

http://ijssurgery.com/content/14/6/853

This information is current as of April 26, 2023.

Email Alerts Receive free email-alerts when new articles cite this article. Sign up at: http://ijssurgery.com/alerts 


\title{
Editor's Introduction: Update on Current Sacroiliac Joint Fusion Procedures: Implications for Appropriate Current Procedural Terminology Medical Coding
}

\author{
MORGAN P. LORIO, MD, FACS \\ ISASS Coding and Reimbursement Chair, Advanced Orthopedics, Altamonte Springs, Florida
}

Over the past decade, a significant number of new devices and products used for minimally invasive surgical (MIS) sacroiliac (SI) joint fusion have entered the market. MIS SI joint fusion with laterally placed transfixing devices, along with data supporting its safety and effectiveness, ${ }^{1-3}$ has impacted how surgeons and other health care providers view the differential diagnosis and treatment of low back pain. There has also been a significant focus on the SI joint fusion market by the medical technology industry. Since 2015, the US market for SI joint fusion procedures has grown between $25 \%$ and $30 \%$ year over year. ${ }^{*}$ This environment has led to rapid evolution of products and a new surgical procedure.

\section{KEY CONCEPTS}

(1) Surgical access for SI joint fusion is either through an open approach/procedure or a minimally invasive approach/procedure. The American Medical Association (AMA) Current Procedural Terminology (CPT) codebook has well-established procedural codes and associated vignettes that describe the different procedures. The code descriptions for the open and MIS procedures and the associated relative value units capture the differences in the intraservice (operative) time, physician work, safety profile, and follow-up clinic visits.

\footnotetext{
*Medicare Frequency (27279: 2015-2018): Utilization from the Medicare Procedures Users File. These data are updated annually and include both the global component and the physicians' (26) component. https://www.ama-assn.org (accessed August 6, 2020).
}

(2) There are 3 different, well-established open surgical approaches to the SI joint (ie, anterior, posterior/“dorsal," and lateral/ "transiliac"). The MIS lateral approach/ procedure is also well established. A new and different approach/procedure, MIS posterior/dorsal, has recently been developed.

(3) US Food and Drug Administration (FDA) regulatory pathways and key distinctions in requirements of FDA review, regulation, and controls (ie, indications, labeling, and claims) are intended to ensure safety and effectiveness of products for SI joint fusion.

(4) Clinicians and the medical coding community should review the appropriateness to report these different procedures as either open (anterior/lateral/posterior), MIS lateral transiliac, or MIS posterior/dorsal with available CPT medical coding.

\section{REVIEW OF SI JOINT ACCESS/ APPROACH (MIS VERSUS OPEN PROCEDURES)}

Certain MIS lateral transiliac approach SI joint procedures used with increasing frequency since $2008^{4}$ have demonstrated a significant improvement in long-term patient outcomes, and have documented both immediate stability ${ }^{5-7}$ and long-term fusion of the SI joint. ${ }^{3,8}$ Strong patient safety profiles have been established for multiple devices using MIS access and a lateral approach. The safety and effectiveness has been demonstrated in randomized controlled trials, ${ }^{1,2}$ a large multicenter trial, ${ }^{9}$ and many case series..$^{8,10-16}$ The durability ${ }^{3,17}$ and 


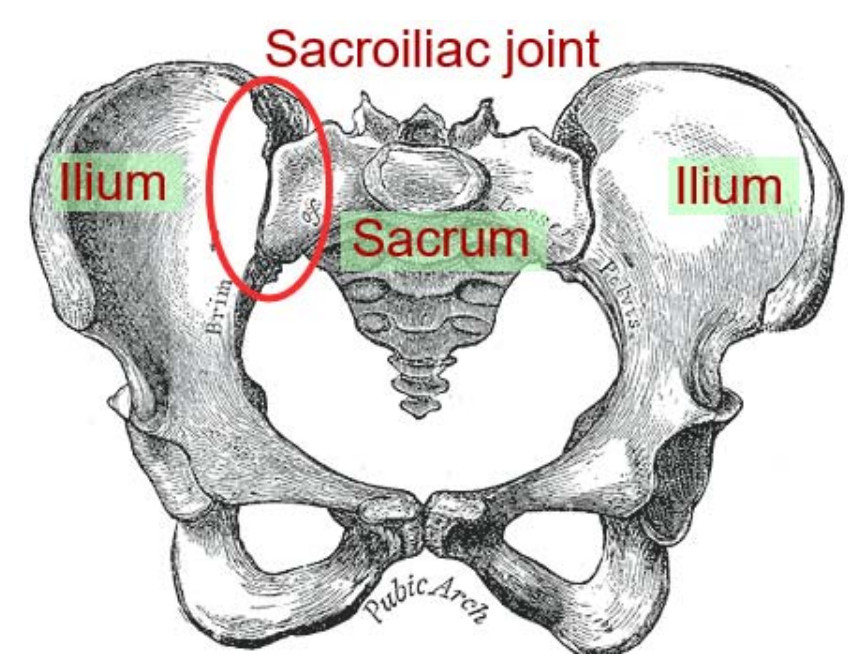

Figure 1. Diagram of the sacroiliac joint (anterior) (https://en.wikipedia.org/ wiki/File:Sacroiliac_joint.svg).

economic benefit ${ }^{18}$ of the iFuse (SI-BONE, Santa Clara, California) lateral device have been described. Collectively, nearly 100 peer-reviewed publications describe the extensive clinical experience with the lateral transiliac approach with placement of transfixing devices.

Several new MIS technologies/products now utilize a novel posterior/dorsal approach to the SI joint. As these products and devices are placed into a different portion of the SI joint from a different trajectory, the anatomic risk profile and safety of the dorsal procedure will be different than the lateral procedure. The safety data for this procedure have not yet been elucidated. The clinical effectiveness of these procedures remains unknown and unclear, as no studies have been published. Most of the products utilize ligamentous distraction as a stabilization strategy. It is not known whether immediate stabilization is achieved or whether these products can lead to long-term fusion. There is additional concern that the highly irregular anatomy of the SI joint may preclude reproducible placement of these products. Given these many differences, the clinical results of the lateral procedure with transfixing devices are not generalizable to the new dorsal procedure.

In certain cases, the open surgical approach/ procedure for SI joint arthrodesis is indicated, including acute trauma, tumor, and infection, as well as for SI joint fusion in conjunction with pelvic fixation in deformity surgery and other indications (Figure 1).

\section{REVIEW OF FDA PATHWAYS FOR MARKETED SI JOINT DEVICES AND PRODUCTS}

Since 2008, the devices and products used in MIS SI joint surgical procedures have evolved. Dozens of new SI joint technologies have entered the market since 2008 through 2 different FDA regulatory pathways. Medical devices are cleared through FDA's Center for Diagnostic and Radiologic Health (CDRH), whereas tissue products, including the several bone allograft products currently on the market for use with the dorsal procedure, are regulated through FDA's Center for Biologics Evaluation and Research:

- FDA CDRH ${ }^{19}$ (responsible for regulating medical devices).

- Section $510(\mathrm{k})$ or premarket notification.

- Section 510(k) of the Food, Drug, and Cosmetic Act (FDCA). A premarket submission is made to the FDA to demonstrate that the device to be marketed is safe and effective, that is, "substantially equivalent," to a legally marketed device (section 513[i][1][A] of the FDCA) and is therefore not subject to premarket approval. Testing data are required.

- Investigational device exemption (21 CFR 812). This is the pathway followed by novel products in order to conduct the clinical trials required for eventual clearance or approval by the FDA. These trials must be approved by an institutional review board and the FDA.

- The medical device reporting (MDR) regulation under 21 CFR 803 requires manufacturers, importers, and device user facilities to report certain device-related adverse events and product problems to the FDA. The regulation also details internal complaints recording requirements for manufacturers.

- FDA $\mathrm{CBER}^{20}$ (responsible for regulating HCT/Ps [human cell and tissue products]).

- Certain HCT/Ps are regulated under Section 361 of the FDCA. These products must meet the criteria for "minimally manipulated tissue" outlined in 21 CFR 1271.10(a) and are not required to be licensed, cleared, or approved by the FDA. No equivalence testing is required, and 


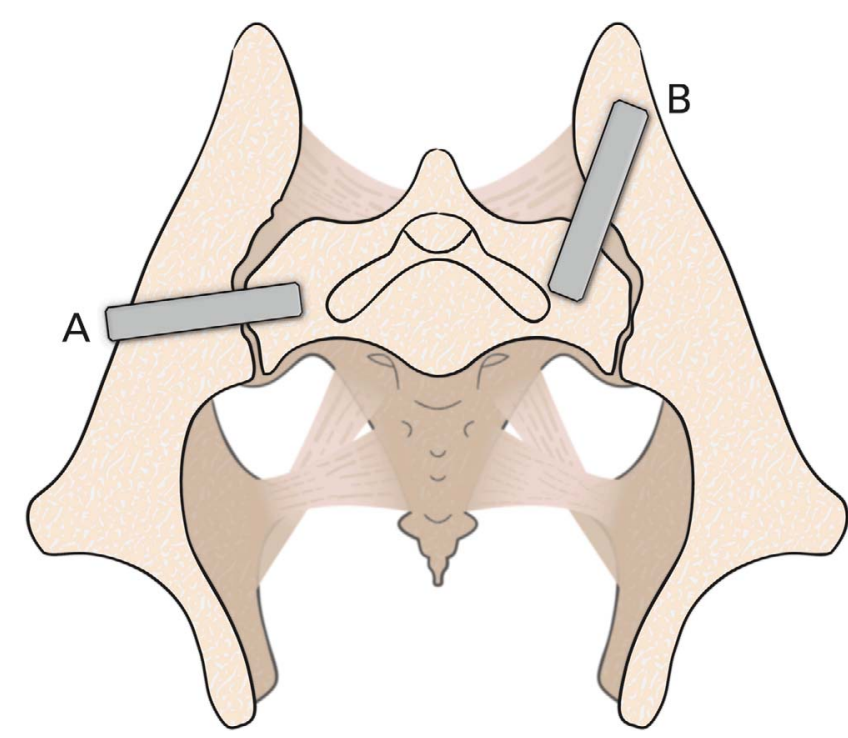

Figure 2. Lateral transiliac transfixing devices. (A) Typical lateral transiliac trajectory. (B) Rialto posterolateral transiliac trajectory.

these are unclassified products per FDA regulations. Their labeling must reflect the manufacturer's intent that they be used only for homologous use (nonspecific to any product claim), that is, that they serve substantially the same function or purpose in the recipient as they did in the donor prior to transplant. Common Section 361 products used in orthopedic procedures include tendon, femoral head allograft, and cancellous bone chips.

- As Section 361 products are not regulated as devices, MDR is not a requirement; however, adverse events can be reported using different mechanisms: biological product deviations or $\mathrm{HCT} / \mathrm{P}$ adverse reaction reporting.

- Section 351 products, on the other hand, do not meet the criteria outlined in 21 CFR 1271.10(a) to be treated as unregulated $\mathrm{HCT} / \mathrm{Ps}$ and are therefore regulated as a "drug, device, or biological product" under the FDCA and Section 351 of the Public Health Service Act. Testing data are required. Common examples of Section 351 products include RHBMP-2 and demineralized bone matrix products.

- Manufacturers of medical devices, like manufacturers of pharmaceuticals, are subject to the Physician Payment Sunshine Act (reference: Section 6002 of the Affordable Care Act, which added Section 1128G to the Social Security Act). The Sunshine
Act requires applicable manufacturers of a covered drug, device, biologic, or medical supply to report payments or other transfers of value to physicians, certain other health care professionals, and teaching hospitals. Manufacturers and distributors of HCT/Ps are not subject to the Sunshine Act's reporting requirements.

Approximately 2 dozen different transfixing devices for MIS SI joint fusion placed via the lateral approach have been cleared through the $510(\mathrm{k})$ FDA pathway since the early 2000s. ${ }^{21}$ All these products are metallic devices that have demonstrated similar mechanical strength on required testing (substantial equivalence). Most are circular in cross section and are threaded into place. One product, the iFuse implant, is triangular in cross section and is impacted into place. Differentiating features between devices may include porous surfaces, fenestrations, and slight variations in implant trajectory and starting point on the ilium. One product, Rialto (Medtronic, Dublin, Ireland), has a starting position that is more posterior on the ilium. This position/trajectory is sometimes described as "posterior," however, the Rialto device enters the ilium laterally, crosses the SI joint, and ends in the sacrum. This placement strategy meets the definition of a lateral transiliac transfixing device (Figure 2).

The majority of the products used for the new posterior, MIS procedure are nonclassified 361 products $(\mathrm{HCT} / \mathrm{Ps})$ indicated only for homologous use. These products are typically placed into the inferior articular limb of the joint posterior inferior, with additional products (grafts) being placed into the ligamentous portion of the joint (between the ilium and the sacrum) directly posterior (Figure 3 ). The ligamentous portion of the joint is disadvantaged from both a biomechanical and a biologic perspective.

This new and different surgical procedure (MIS posterior/dorsal SI joint fusion), with unknown safety and effectiveness, using different products, and with a different stabilization/fusion strategy (distraction arthrodesis), has prompted further review of existing (and historical) CPT medical coding intended to describe SI joint fusion procedures.

\section{DISCUSSION: SI JOINT FUSION PROCEDURES AND CPT CODING}

Since the early 1900s, open surgical approaches for SI joint arthrodesis have been reported in the 


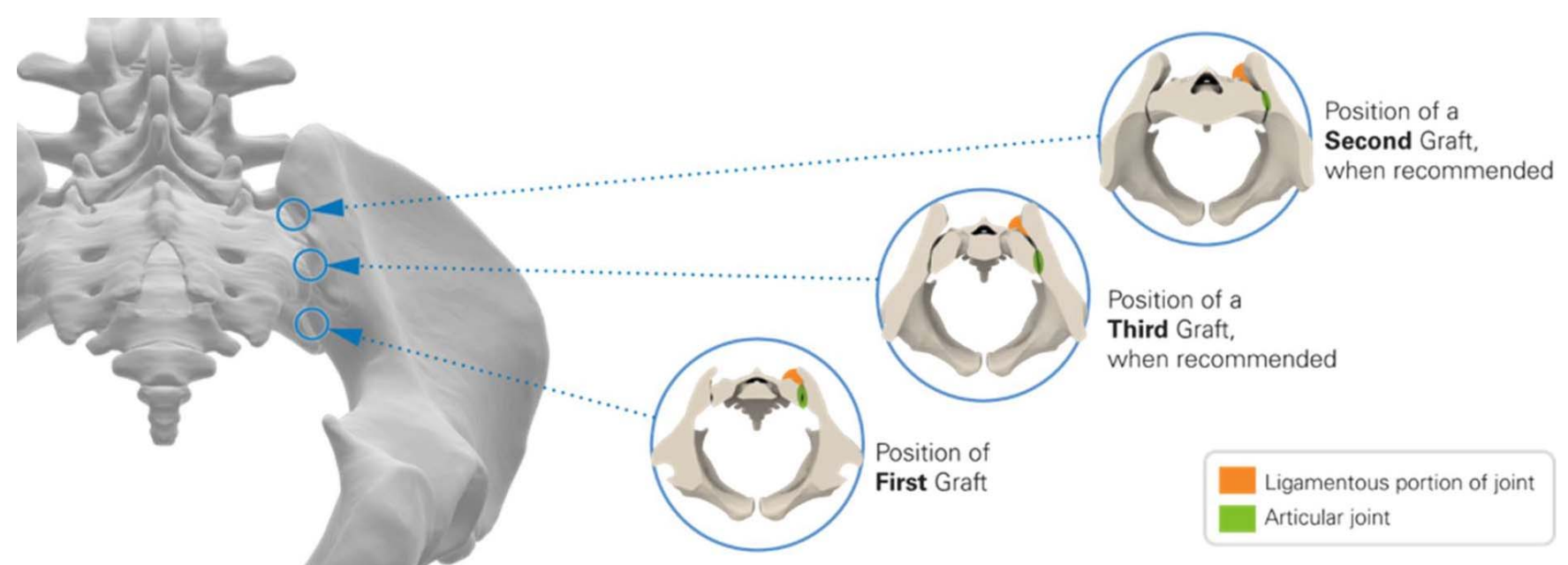

Figure 3. Position of minimally invasive surgical posterior/“dorsal” products.

clinical literature. These have included anterior, ${ }^{22,23}$ lateral transiliac ${ }^{24,25}$ and posterior ${ }^{26}$ approaches analogous to surgical approaches to the lumbar spine. The open surgical procedure, whether from an anterior, a lateral, or a posterior approach, requires a large incision and extensive surgical dissection and is associated with increased surgical time and patient morbidity. All 3 open surgical approaches are described by CPT code 27280 . These open surgical approaches provide open surgical access to a large portion of the articular SI joint to facilitate fracture reduction in the case of trauma and osteoclasis and bone grafting in the case of elective fusion. As surgical practice has evolved, so too have the fixation techniques utilized with these open surgical procedures. Numerous articles have reviewed the utilization and clinical outcomes of open surgical procedures for SI joint fusion. There are recently published studies comparing the outcomes of patients treated with open versus MIS fusion procedures. ${ }^{27-29}$

In 1993, the AMA developed the CPT code to report open SI joint arthrodesis procedures:

CPT 27280, Arthrodesis, open, sacroiliac joint, including obtaining bone graft, including instrumentation, when performed ${ }^{\dagger}$

CPT 27280 was used to describe the open procedure available at the time. This included the

\footnotetext{
†In 2015, the AMA added the phrases "open" and "including instrumentation, when performed." Prior to 2015, the description for CPT 27280 was "Arthrodesis, sacroiliac joint (including obtaining graft).”
}

posterior, anterior, and lateral transiliac approaches.

In 2008, the FDA awarded 510(k) clearance to the iFuse Implant System (SI-BONE), one of the first MIS lateral transiliac devices for SI joint fusion." Since that time, more than 20 additional devices have been cleared for SI joint fusion. ${ }^{\S}$ In 2012, the North American Spine Society (NASS) recommended that MIS SI joint fusion with laterally placed transfixing devices be coded with the unlisted spine code CPT 22899, based on differences in intraservice time, physician work, and postoperative visits." In 2012, ${ }^{30}$ the AMA issued a temporary Category III HCPCS code (0334T) to describe and to track these "MIS lateral" SI joint fusion procedures while level I and II data were being further developed.

In 2014, ${ }^{31}$ the AMA CPT Editorial Panel was presented with sufficient published clinical evidence from multiple ongoing randomized controlled and prospective clinical trials to support the issuance of a permanent Category I CPT code to report the

tFDA 510(k) Premarket Notification Database: K080398and K092375 (accessed August 6, 2020).

${ }^{\S}$ Companies marketing SI joint devices: SI-BONE, Medtronic, Globus Medical, Xtant, Surgalign (previously RTI), Alevio, CoreLink, Orthofix/Medical Designs, Camber Medical, VG Innovations, Zimmer Biomet, Captiva Spine, Coorstek, Life Spine, SICage, Signus, SpineFrontier, SITechnology, Medacta, Frontier Devices, L\&K Biomed, Zavation, Huvexel, and Tenon Medical.

NASS Common Coding Scenarios for Comprehensive Spine Care 2012. See also https://www.aapc.com/discuss/threads/ implants-included-in-sacroiliac-fusion. 72383. 
Table 1. Surgical approach and access to the sacroiliac joint (and available CPT coding).

\begin{tabular}{lccccc}
\hline & Open Access & & \multicolumn{2}{c}{ MIS Access } \\
\cline { 2 - 2 } \cline { 5 - 6 } Approach & $\mathbf{2 7 2 8 0}$ & & $\mathbf{2 7 2 7 9}$ & Unlisted \\
\hline Anterior & $\mathrm{X}$ & & - & - \\
Posterior & $\mathrm{X}$ & & $\mathrm{X}$ & & - \\
Lateral (transiliac, "transfixing") & & & - \\
\hline
\end{tabular}

Abbreviations: CPT, Current Procedural Terminology; MIS, minimally invasive surgical. - , indicates not applicable.

MIS lateral SI joint fusion procedures, which utilized transiliac "transfixing devices" advanced from the ilium, through the SI joint, and into the sacrum:

CPT 27279, Arthrodesis, sacroiliac joint, percutaneous or minimally invasive (indirect visualization), with image guidance, includes obtaining bone graft when performed, and placement of transfixing device) (emphasis added)

The MIS dorsal procedure had not yet been popularized, and there were no FDA-cleared devices and no $\mathrm{HCT} / \mathrm{P}$ products being marketed for the dorsal SI joint fusion procedure at that time.

During this same CPT Panel meeting, which added CPT 27279, the AMA also clarified CPT 27280 to better describe the characteristics of the open surgical procedure, including incision size extending "two-thirds of the iliac crest" $(8 \mathrm{~cm}$ or more) as well as updated intraservice vignettes describing open-access anterior and lateral approaches.

Minimally invasive procedures, in contrast, are performed with small incisions and minimal dissection and do not provide open access to the articular SI joint. The new minimally invasive dorsal procedures are frequently miscoded as open procedures. This is disingenuous, as the MIS dorsal procedure meets neither the letter nor the spirit of the open procedure as described by CPT 27280 . The MIS dorsal procedure (regardless of product or device) utilizes a small (1-2-cm) incision with minimal surgical dissection for placement of a piece of allograft into the inferior articular limb of the joint. The articular joint is accessed through a small opening of the joint capsule, and the graft is placed between the articular surfaces. There is no open access to the joint with this MIS dorsal procedure, and only the lateral most margin of the joint, where the 2 surfaces come together, is visualized. Some products ask that additional bone graft(s) be placed into the ligamentous portion of the joint, well away from the articular portion of the joint, again through small incisions. These MIS dorsal procedures are typically performed in the ambulatory surgical center setting and are performed quickly with minimal patient morbidity. These procedures likely are not reflective of the physician time data underpinning the valuation of the 27280 code, which were based on primarily hospital inpatient procedures, and include 120 minutes of intraservice (operative) time and significant physician work. Open SI joint fusion procedures are associated with increased patient morbidity, an inpatient hospital stay of 2-4 days, and an increased number of follow-up patient visits.

Therefore, it is clear the existing CPT code 27280 describes an open SI joint fusion procedure from multiple different approaches and that CPT code 27279 has been established to describe MIS SI joint procedures that utilize a lateral transiliac approach (Table 1). Providers describing MIS SI joint fusion procedures that do not utilize a lateral or transiliac "transfixing device" approach should report with an unlisted CPT code."

More research on this evolving topic may help clarify for surgeons when to use the new dorsal procedure, particularly once data on patient safety and clinical effectiveness become available. Clinical evidence will also help clarify for medical coding communities how best to report and describe this new procedure. The integrity of the CPT coding process depends on use of the code that best describes the procedure performed. Use of the proper CPT code, including permanent, temporary, or unlisted codes, is dependent on operative notes accurately describing the procedure performed, the type of surgical access (open versus MIS), and the surgical approach (MIS lateral procedure or new MIS posterior procedure). Future development of new or revised CPT coding may be appropriate.

\section{REFERENCES}

1. Dengler J, Kools D, Pflugmacher R, et al. Randomized trial of sacroiliac joint arthrodesis compared with conservative management for chronic low back pain attributed to the

\footnotetext{
\#Use 27299 (unlisted procedure, pelvis or hip joint) or 22899 (unlisted procedure, spine) for reporting. Per AMA CPT Instructions for Use, if a procedure or service is not accurately described by an existing code, the unlisted code should be used in its place. An existing code should not be selected if it merely approximates the service provided.
} 
sacroiliac joint. J Bone Joint Surg Am. 2019;101(5):400-411. doi:10.2106/JBJS.18.00022

2. Polly DW, Swofford J, Whang PG, et al. Two-year outcomes from a randomized controlled trial of minimally invasive sacroiliac joint fusion vs. non-surgical management for sacroiliac joint dysfunction. Int J Spine Surg. 2016;10:28. doi:10.14444/3028

3. Whang PG, Darr E, Meyer SC, et al. Long-term prospective clinical and radiographic outcomes after minimally invasive lateral transiliac sacroiliac joint fusion using triangular titanium implants. Med Devices (Auckl). 2019;12:411-422. doi:10.2147/MDER.S219862

4. Lorio MP, Polly DW Jr, Ninkovic I, Ledonio CGT, Hallas K, Andersson G. Utilization of minimally invasive surgical approach for sacroiliac joint fusion in surgeon population of ISASS and SMISS membership. Open Orthop J. 2014;8:1-6. doi:10.2174/1874325001408010001

5. Lindsey D, Perez-Orribo L, Rodriquez-Martinez N, et al. Evaluation of a minimally invasive procedure for sacroiliac joint fusion - an in vitro biomechanical analysis of initial and cycled properties. Med Devices (Auckl). 2014;2014(7):131-137. doi:10.2147/MDER.S63499

6. Bruna-Rosso C, Arnoux P-J, Bianco R-J, GodioRaboutet Y, Fradet L, Aubin C-É. Finite element analysis of sacroiliac joint fixation under compression loads. Int J Spine Surg. 2016;10:16. doi:10.14444/3016

7. Shih YC, Beaubien BP, Chen Q, Sembrano JN. Biomechanical evaluation of sacroiliac joint fixation with decortication. Spine J. 2018;18(7):1241-1249. doi:10.1016/j. spinee.2018.02.016

8. Rudolf L, Capobianco R. Five-year clinical and radiographic outcomes after minimally invasive sacroiliac joint fusion using triangular implants. Open Orthop J. 2014;8:375383. doi:10.2174/1874325001408010375

9. Duhon BS, Bitan F, Lockstadt H, Kovalsky D, Cher D, Hillen T. Triangular titanium implants for minimally invasive sacroiliac joint fusion: 2-year follow-up from a prospective multicenter trial. Int J Spine Surg. 2016;10:13. doi:10.14444/ 3013

10. Rappoport LH, Luna IY, Joshua G. minimally invasive sacroiliac joint fusion using a novel hydroxyapatite-coated screw: preliminary 1-year clinical and radiographic results of a 2-year prospective study. World Neurosurg. 2017;101:493-497. doi:10.1016/j.wneu.2017.02.046

11. Rajpal S, Burneikiene S. Minimally invasive sacroiliac joint fusion with cylindrical threaded implants using intraoperative stereotactic navigation. World Neurosurg. 2020;135:387388. doi:10.1016/j.wneu.2018.11.116

12. Araghi A, Woodruff R, Colle K, et al. Pain and opioid use outcomes following minimally invasive sacroiliac joint fusion with decortication and bone grafting: the Evolusion Clinical Trial. Open Orthop J. 2017;11(1):1440-1448. doi:10. 2174/1874325001711011440

13. Abbasi H, Hipp JA. The assessment of fusion following sacroiliac joint fusion surgery. Cureus. 2017;9(10):e1787. doi:10. 7759/cureus. 1787

14. Kube RA, Muir JM. Sacroiliac joint fusion: one year clinical and radiographic results following minimally invasive sacroiliac joint fusion surgery. Open Orthop J. 2016;10(1). doi: $10.2174 / 1874325001610010679$

15. Bornemann R, Roessler PP, Strauss A, et al. 2-year clinical results of patients with sacroiliac joint syndrome treated by arthrodesis using a triangular implant system. Technol Health Care. 2017;25(2):319-325. doi:10.3233/THC-161272

16. Sachs D, Capobianco R. Minimally invasive sacroiliac joint fusion: one-year outcomes in 40 patients. Adv Orthop. 2013;2013:536128. doi:10.1155/2013/536128

17. Vanaclocha V, Herrera JM, Sáiz-Sapena N, Rivera-Paz M, Verdú-López F. Minimally invasive sacroiliac joint fusion, radiofrequency denervation, and conservative management for sacroiliac joint pain: 6-year comparative case series. Neurosurgery. 2018;82(1):48-55. doi:10.1093/neuros/nyx 185

18. Cher DJ, Polly DW. Improvement in health state utility after sacroiliac joint fusion: comparison to normal populations. Global Spine J. 2016;6(2):100-107. doi:10.1055/s-0035-1556581

19. US Food and Drug Administration Center for Devices and Radiological Health. https://www.fda.gov/about-fda/fdaorganization/center-devices-and-radiological-health. Accessed August 6, 2020.

20. US Food and Drug Administration Center for Biologics Evaluation and Research. https://www.fda.gov/about-fda/fdaorganization/center-biologics-evaluation-and-research-cber. Accessed August 6, 2020.

21. FDA 501(k) Premarket Notification Database: Product Code "OUR." https://www.accessdata.fda.gov/scripts/cdrh/ cfdocs $/$ cfpmn $/$ pmn.cfm?start_search $=1 \&$ Center $=\&$ Panel $=\&$ ProductCode $=$ OUR $\&$ KNumber $=\&$ Applicant $=\&$ DeviceName $=\&$ Type $=\&$ ThirdParty Reviewed $=\&$ ClinicalTrials $=\&$ Decision $=\&$ DecisionDateFrom $=\&$ DecisionDateTo $=08 \% 2 \mathrm{~F} 02 \% 2 \mathrm{~F} 2020 \&$ IVDProducts $=\&$ Redact $510 \mathrm{~K}=\&$ CombinationProducts $=\&$ ZNumber $=\& P A G E N U M=100 \&$ sortcolumn=dd_desc. Accessed August 7, 2020.

22. Avila L. Primary pyogenic infection of the sacro-iliac articulation. A new approach to the joint. J Bone Joint Surg. 1941;23(4):922-928.

23. Rand JA. Anterior sacro-iliac arthrodesis for posttraumatic sacro-iliac arthritis. A case report. J Bone Joint Surg Am. 1985;67(1):157-159.

24. Smith-Petersen MN. Arthrodesis of the sacroiliac joint. A new method of approach. J Bone Joint Surg Am. 1921;3(8):400-405.

25. Gaenslen FJ. Sacro-iliac arthrodesis: indications, author's technic and end-results. JAMA. 1927;89(24):2031-2035.

26. Painter CF. Excision of the os innominatum. Arthrodesis of the sacro-iliac synchrondrosis. Boston Med Surg J. 1908;159(7):205-208.

27. Graham Smith A, Capobianco R, Cher D, et al. Open versus minimally invasive sacroiliac joint fusion: a multi-center comparison of perioperative measures and clinical outcomes Ann Surg Innov Res. 2013;7(1):14. doi:10.1186/1750-1164-7-14

28. Ledonio C, Polly D, Swiontkowski MF, Cummings J. Comparative effectiveness of open versus minimally invasive sacroiliac joint fusion. Med Devices (Auckl). 2014(7):187-193. doi:10.2147/MDER.S60370

29. Ledonio CGT, Polly DW, Swiontkowski MF. Minimally invasive versus open sacroiliac joint fusion: are they similarly safe and effective? Clin Orthop Relat Res. 2014;472(6):18311838. doi:10.1007/s11999-014-3499-8

30. American Medical Association CPT Editorial Summary of Panel Actions October, 2012. https://www.ama-assn.org/ sites/ama-assn.org/files/corp/media-browser/public/cpt/oct2012-cpt-panel-action-memo_0.pdf. Accessed August 6, 2020.

31. American Medical Association CPT Editorial Summary of Panel Actions February, 2014. https://www.ama-assn.org/ 
sites/ama-assn.org/files/corp/media-browser/public/cpt/ summary-of-panel-actions-feb2014_0.pdf. Accessed August 6, 2020 .

Disclosures and COI: Consulting/SAB Vivex. Corresponding Author: Morgan P. Lorio, MD, FACS, Chair, ISASS Coding and Reimbursement, Advanced Orthopedics, 499 East Central
Parkway, Altamonte Springs, FL 32701. Phone: (407) 960-1717; Email: Mloriomd@gmail.com.

Published 22 January 2021

This manuscript is generously published free of charge by ISASS, the International Society for the Advancement of Spine Surgery. Copyright (c) 2020 ISASS. To see more or order reprints or permissions, see http://ijssurgery.com. 